\title{
On-Site Calibration Method of Dosimeter Based on X-Ray Source
}

\author{
Wenhui Lv, Huiping Guo, Ning Lv, Chenyang Tian, Kuo Zhao, Xiaotian Wang, Yijie Hou \\ Xi'an Research Institute of Hi-Tech, Xi'an, China \\ Email:lvwenhui10@163.com
}

How to cite this paper: Lv, W.H., Guo, H.P., Lv, N., Tian, C.Y., Zhao, K., Wang, X.T. and Hou, Y.J. (2017) On-Site Calibration Method of Dosimeter Based on X-Ray Source. World Journal of Nuclear Science and Technology, 7, 93-102.

http://doi.org/10.4236/wjnst.2017.72008

Received: January 16, 2017

Accepted: April 16, 2017

Published: April 20, 2017

Copyright $\odot 2017$ by authors and Scientific Research Publishing Inc. This work is licensed under the Creative Commons Attribution International License (CC BY 4.0).

http://creativecommons.org/licenses/by/4.0/

\begin{abstract}
The real-time monitoring of environmental radiation dose for nuclear facilities is an important part of safety, in order to guarantee the accuracy of the monitoring results regular calibration is necessary. Around nuclear facilities there are so many environmental dosimeters installed dispersedly, because of its huge quantity, widely distributed, and in real-time monitoring state; it will cost lots of manpower and finance if it were taken to calibrate on standard laboratory; what's more it will make the environment out of control. To solve the problem of the measurement accuracy of the stationary gamma radiation dosimeter, an on-site calibration method is proposed. The radioactive source is $\mathrm{X}$-ray spectrum, and the dose reference instrument which has been calibrated by the national standard laboratory is a high pressure ionization. On-site calibration is divided into two parts; firstly the energy response experiment of dosimeter for high and low energy is done in the laboratory, and the energy response curve is obtained combining with Monte Carlo simulation; secondly experiment is carried out in the field of the measuring dosimeter, and the substitution method to calibrate the dosimeter is used; finally the calibration coefficient is gotten through energy curve correction. In order to verify the accuracy of on-site calibration method, the calibrated dosimeter is test in the standard laboratory and the error is $3.4 \%$. The result shows that the on-site calibration method using X-ray is feasible, and it can improves the accuracy of the measurement results of the stationary $\gamma$-ray instrument; what's more important is that it has great reference value for the radiation safety management and radiation environment evaluation.
\end{abstract}

\section{Keywords}

X Ray Source, On-Site Calibration, Energy Response, Gamma Radiation Dosimeter 


\section{Introduction}

The level of environment gamma dose monitoring is an important part of the nuclear safety management, the results can provide data support for personnel dose assessment and environmental radioactivity evaluation, and it is also a reference basis for taking measures of radiation protection and radiation safety management, so the measuring accuracy of the instrument is very important. In the process of using the instrument, the performance parameters will change due to material loss and electronic circuit aging. In order to improve the accuracy of the measurement results, the gamma dose instruments should be calibrated regularly [1].

The traditional method is to calibrate the dosimeter in national standard laboratory [2] [3], however it has the following problems [4]:

1) Some instruments are installed distribution and they are in the state of real-time monitoring, however laboratory calibration is time consuming, if the instruments are taken to the laboratory will make the environment out of control.

2) The detector is connected with the data processing system, and it is difficult to move.

3) The dosimeter is calibrated about once a year; frequent disassembly and transportation will increase the probability of failure.

To solve this problem, on-site calibration method of dose instrument was developed at home. Gao Fei and Xiao Xuefu [5] [6] of China Institute of Atomic Energy studied on-site calibration technology of environmental dose instrument and developed a portable device of radioactive source [7] [8]. Rong Yonghua of China Institute of Atomic Energy researched on-site calibration technology of experimental fast reactor gamma dosimeter. Zhao Chao of Shanghai Institute of measurement and testing technology improved gamma source irradiation device based on the optimization design, which has accurate positioning and remote control shift function, and the weight of the device is greatly reduced [9]. Jin Chenghe of China Institute for radiation protection developed a portable multi-range reference irradiation device for on-site calibration.

The portable radioactive sources mentioned above are using isotope sources, which have the following problems: Firstly the energy of the source is single, usually the calibration should use two or more energy points, furthermore the supervision of the isotope source is very strict, and rays are emitting all the time, once a nuclear accident happens, it will cause great radiation damage to people. Though shielding method is used to control the radiation hazard, the security risks still exist during the management and transportation of the source. Considering reliability and radiation safety, the radiation damage to the staff and the public in the calibration process should reduce as far as possible, so the on-site calibration method combined with energy response correction based on X-ray source is proposed [10]. The X-ray source is portable and controllable, and is has no radiation damage to human and environment when it is not work. This paper studies how to make use of low energy $\mathrm{X}$ ray to carry out on-site calibration of the full range of the instrument. 


\section{Calibration Theory}

The energy response of a dose instrument is the ratio of conventional true value to the display value of the instrument at the monitoring point under the condition of specific energy and unidirectional radiation. The detector has different energy response for gamma rays with different energies, for the same intensity of incident gamma rays with different energies the detector's output may be different, but as a linear time invariant system the output signal of the detector is proportional to the gamma ray intensity. That is:

$$
S_{0}=S_{\gamma} \cdot S_{i}
$$

where, $S_{0}$ and $S_{i}$ are intensities of output signal and input signal of the measurement system, $S_{\gamma}$ is the sensitivity of the system for gamma ray with specific spectrum.

From the formula we can see that for a specific energy spectrum (including single spectra and coincidence spectra), if the gamma spectrum response of the system is known, then the output of the system can be calibrated with a specific energy spectrum.

Based on this, on-site calibration process is divided into two steps: 1) Calibrate the reference instrument in standard laboratory to meet the requirements of metering value transfer. Then study the energy response of the instrument through experiment and Monte Carlo simulation to obtain the energy response curve [11]. 2) Calibrate the dose instrument using substitution method in the field and get the calibration coefficient, then revise the calibration coefficient through the energy response curve [12]. The calibration flow chart is shown in Figure 1.

\section{X Ray Radiation Characteristics}

$\mathrm{X}$ ray is produced by $\mathrm{X}$ ray unit, its energy and beam intensity can adjust with the change of tube voltage and tube current. However, the energy of $\mathrm{X}$ ray is low and it is usually used in calibration of low energy for the dosimeter. GB/T $12,162.1$ gives the reference performance of filter $\mathrm{X}$ ray spectrum from $7 \mathrm{keV}$ to $250 \mathrm{keV}$, and it makes the relevant explanation for the characteristics of $\mathrm{X}$ ray unit [13], radiation field and scattered radiation. The $\mathrm{X}$ ray used in this research is based on the recommended value of national standard, its radiation characteristics is shown in Table 1.

\section{Energy Response Curve of Gamma Dosimeter}

When the $\mathrm{X}$ ray is used to calibrate the dose instrument, because of the energy of the $\mathrm{X}$ ray is low and it only covers the low energy area of the instrument, which makes the calibration results inaccurate. To solve this problem, this research combines Monte Carlo simulation and experiment for obtaining the energy response curve of the instruments, and using it to revise the on-site calibration coefficient to achieve on-site calibration of the gamma dosimeter. 

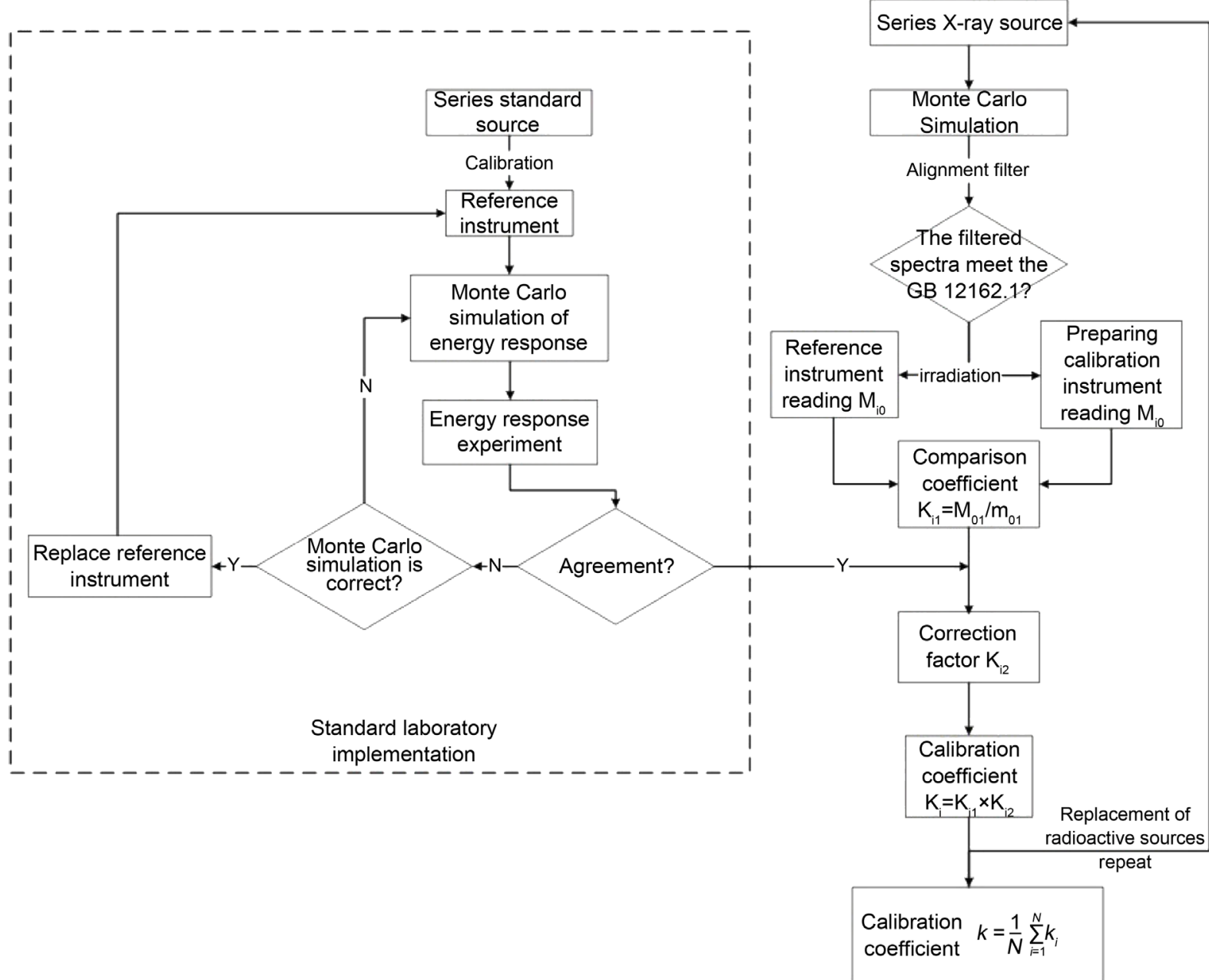

Figure 1. Flow chart of on-site calibration method.

Table 1. Radiation characteristics of X-ray source.

\begin{tabular}{cccc}
\hline Tube Voltage $/ \mathrm{kV}$ & Average Energy $/ \mathrm{keV}$ & Resolution/\% & Additional Filtration \\
\hline 70 & 60 & $22 \%$ & $2.5 \mathrm{~mm} \cdot \mathrm{Cu}$ \\
100 & 87 & $22 \%$ & $2.0 \mathrm{~mm} \cdot \mathrm{Sn}+0.5 \mathrm{~mm} \cdot \mathrm{Cu}$ \\
125 & 109 & $21 \%$ & $4.0 \mathrm{~mm} \cdot \mathrm{Sn}+1.0 \mathrm{~mm} \cdot \mathrm{Cu}$ \\
240 & 211 & $18 \%$ & $5.5 \mathrm{~mm} \cdot \mathrm{Pb}+2.0 \mathrm{~mm} \cdot \mathrm{Sn}+0.5 \mathrm{~mm} \cdot \mathrm{Al}$ \\
\hline
\end{tabular}

\subsection{Energy Response Experiment}

To obtain the response of the instrument for different energy of $\mathrm{X}$ ray, the energy response of the dose instrument was measured using different energy of $\mathrm{X} / \gamma$ ray. The energy response test of the low energy region of the instrument was carried out at the China Institute of Atomic Energy, while the high energy area was done at Northwest Institute of nuclear technology. The results of the experiment are listed in Table 2.

The experimental results show that the kerma rate value of the radiation source with $70 \mathrm{kV}$ voltage is lower than conventional true value, the reason is that the $\mathrm{X}$ ray has certain spectrum broadening, low energy ray is absorbed by 
aluminum shell, making the output of the detector is low, therefore it will be cancelled.

\subsection{Monte Carlo Simulation}

To obtain the energy response curve of the detector, Geant4 [14] is used to simulate the response of the detector to different energy gamma rays [15] [16]. The detector is a high pressure ionization chamber, which consists of a central electrode, a gas medium and a shell. The central electrode is a cylindrical structure and its material is aluminum, the shell of the detector is made of stainless steel, between the shell and the central electrode is filled with 20 atmospheres of pure argon. The schematic diagram of the detector structure is shown in Figure 2.

The simulation results of the energy response are shown in Table 3.

Table 2. Experimental results of the response of $\mathrm{X} / \gamma$ source with different energies.

\begin{tabular}{|c|c|c|c|c|c|c|c|c|}
\hline \multirow{2}{*}{ Radiation Source } & \multicolumn{6}{|c|}{ Kerma Rate $/ \mu \mathrm{Gy} \cdot \mathrm{h}^{-1}$} & \multirow{2}{*}{$\begin{array}{c}\text { Average } \\
\text { Value/ } \mu \mathrm{Gy} \cdot \mathrm{h}^{-1}\end{array}$} & \multirow{2}{*}{ Conventional True Value $/ \mu \mathrm{Gy} \cdot \mathrm{h}^{-1}$} \\
\hline & 1 & 2 & 3 & 4 & 5 & 6 & & \\
\hline L70 & \multicolumn{6}{|c|}{13.6613 .6413 .6513 .6513 .6413 .64} & 13.65 & 40 \\
\hline L100 & \multicolumn{6}{|c|}{45.5145 .5345 .5145 .5745 .5345 .57} & 45.54 & 38.88 \\
\hline L125 & \multicolumn{6}{|c|}{52.6652 .6852 .6652 .6252 .6452 .68} & 52.66 & 41.93 \\
\hline $\mathrm{L} 240$ & \multicolumn{6}{|c|}{44.244 .1844 .1844 .244 .1844 .22} & 44.19 & 46.81 \\
\hline${ }^{60} \mathrm{Co}$ & \multicolumn{6}{|c|}{525.0521 .6523 .3524 .1520 .8522 .5} & 522.9 & 584.4 \\
\hline
\end{tabular}

Table 3. Simulation of the energy response of the detector.

\begin{tabular}{ccc}
\hline Radiation Source & Average Energy/keV & Response Value \\
\hline L100 & 87 & 0.860 \\
L125 & 109 & 1.038 \\
L240 & 211 & 0.742 \\
${ }^{60}$ Co & 1250 & 0.640 \\
\hline
\end{tabular}

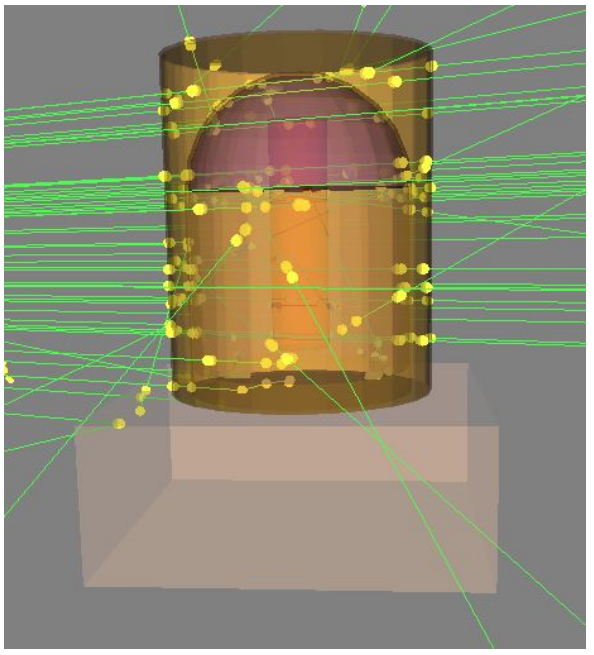

Figure 2. The schematic diagram of the detector structure. 


\subsection{Energy Response Correction}

The results of the simulation and experiment are show in Table 4.

From the results we know that the simulation of the energy response value is lower than experiment, the reason is that the output of the detector is kerma rate, and it has been converted by intrinsic calibration factor.

The response of the simulation and experiment is consistent with the change of the energy, and its correlation coefficient is 0.96 . The simulation results are corrected using least square method and the correction coefficient is 1.29. The revised energy response value is shown in Figure 3.

Based on the correction coefficient obtained by experiment, the energy response curve is simulated using Geant 4 and the result is shown in Figure 4.

In order to further verify the energy response value after experiment correction, the experiment of energy response using ${ }^{137} \mathrm{Cs}$ source was carried out at Northwest Institute of nuclear technology [17], and the results are shown in Table 5.

The experiment results show that the detector response value for ${ }^{137} \mathrm{Cs}$ source is 0.848 , however the modified simulation response value is 0.839 and its error is $1.06 \%$. It is verified that the method of combining experiment and Monte Carlo simulation to obtain energy response curve is feasible.

\section{On-Site Calibration}

\subsection{On-Site Calibration Coefficient}

Take the reference instrument and $\mathrm{X}$ ray unit to the field measurement, and use

Table 4. Energy response of simulation and experiment.

\begin{tabular}{ccc}
\hline \multirow{2}{*}{ Radiation source } & \multicolumn{2}{c}{ Response value } \\
\cline { 2 - 3 } & Simulation & Experiment \\
\hline L100 & 0.860 & 1.171 \\
L125 & 1.038 & 1.256 \\
L240 & 0.742 & 0.944 \\
${ }^{60} \mathrm{Co}$ & 0.640 & 0.894 \\
\hline
\end{tabular}

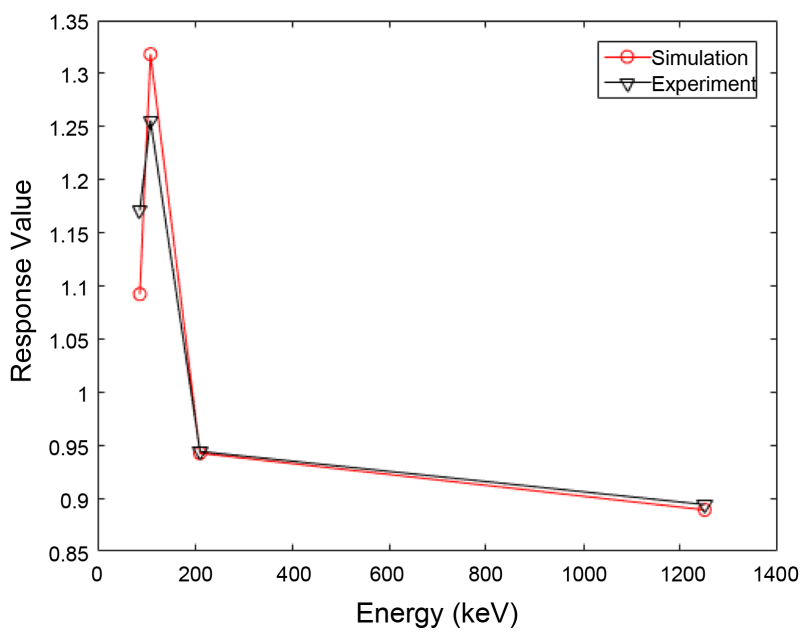

Figure 3. Revised energy response value. 
$\mathrm{X}$-ray with voltage of $100 \mathrm{kV}, 125 \mathrm{kV}, 240 \mathrm{kV}$ as radiation source to irradiate the reference instrument and measuring instrument respectively, note that the experiment conditions are the same in the irradiation process. The experiment results are shown in Table 6 .

The calibration coefficients are different for different $\mathrm{X}$ ray energies, mainly because the response of the detector is different in the low energy region.

\subsection{Calibration Coefficient Correction}

Usually ${ }^{137} \mathrm{Cs}$ or ${ }^{60} \mathrm{Co}$ source is used as source for calibrating the dose instrument, however the response of dose instrument is quite different for different energies of $\mathrm{X}$ or gamma ray, so the results will be corrected to source of ${ }^{137} \mathrm{Cs}$ or ${ }^{60} \mathrm{Co}$ based on the energy response curve, as shown in Table 7.

The calibration coefficient of the instrument relative to ${ }^{137} \mathrm{Cs}$ is

$$
K_{1}=\frac{1}{3} \sum_{i=1}^{3} k_{i}=\frac{1.69+1.66+1.67}{3}=1.67
$$

The calibration coefficient of the instrument relative to ${ }^{60} \mathrm{Co}$ is

$$
K_{2}=\frac{1}{3} \sum_{i=1}^{3} k_{i}=\frac{1.64+1.71+1.69}{3}=1.68
$$

The calibration coefficient after correction is 1.675.

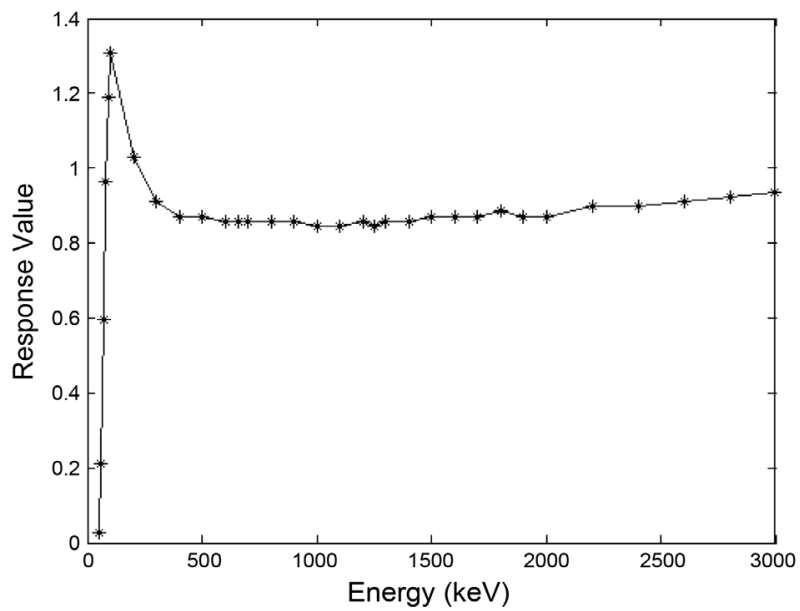

Figure 4. Energy response curve.

\begin{tabular}{|c|c|c|c|c|c|c|c|c|}
\hline \multirow{2}{*}{ Radiation Source } & \multicolumn{6}{|c|}{ Kerma Rate $/ \mu \mathrm{Gy} \cdot \mathrm{h}^{-1}$} & \multirow{2}{*}{$\begin{array}{c}\text { Average } \\
\text { Value } / \mu \mathrm{Gy} \cdot \mathrm{h}^{-1}\end{array}$} & \multirow{2}{*}{ Conventional True Value $/ \mu \mathrm{Gy} \cdot \mathrm{h}^{-1}$} \\
\hline & 1 & 2 & 3 & 4 & 5 & 6 & & \\
\hline${ }^{60} \mathrm{Co}$ & 3.83 & .83 & .83 & .83 & 3.833 & .832 & 3.833 & 4.52 \\
\hline
\end{tabular}

Table 5. Experimental results of verification of energy response curves.

Table 6. Measurement value of the dosimeter with different high pressure.

\begin{tabular}{cccc}
\hline Tube Voltage $/ \mathrm{kVMeasured}$ Instrument $/ \mu \mathrm{Gy} \cdot \mathrm{h}^{-1}$ Reference Instrument $/ \mu \mathrm{Gy} \cdot \mathrm{h}^{-1}$ Calibration Coefficient \\
\hline 100 & 17.20 & 38.75 & 2.25 \\
125 & 15.69 & 42.02 & 2.68 \\
240 & 24.63 & 46.74 & 1.90 \\
\hline
\end{tabular}


Table 7. Energy response correction factor.

\begin{tabular}{cccccc}
\hline \multirow{2}{*}{$\begin{array}{c}\text { Tube } \\
\text { Voltage/keV }\end{array}$} & Calibration & Coefficient & \multicolumn{2}{c}{ Energy Response Correction Factor } & \multicolumn{2}{c}{ Correction Calibration Factor } \\
\cline { 3 - 6 } & ${ }^{137} \mathrm{Cs}$ & ${ }^{60} \mathrm{Co}$ & ${ }^{137} \mathrm{Cs}$ & ${ }^{60} \mathrm{Co}$ \\
100 & 2.25 & 0.75 & 0.73 & 1.69 & 1.64 \\
125 & 2.68 & 0.62 & 0.64 & 1.66 & 1.71 \\
240 & 1.90 & 0.88 & 0.89 & 1.67 & 1.69 \\
Average Value & - & - & - & 1.67 & 1.68 \\
\hline
\end{tabular}

Table 8. Verified experimental of results of on-site calibration.

\begin{tabular}{cccc}
\hline Source & Laboratory Calibration Coefficient & On-site Calibration Coefficient & Relative Error \\
\hline${ }^{137} \mathrm{Cs}$ & 1.63 & 1.67 & $2.45 \%$ \\
${ }^{60} \mathrm{Co}$ & 1.61 & 1.68 & $4.35 \%$ \\
\multirow{2}{*}{ Average Value } & 1.620 & 1.675 & $3.40 \%$ \\
\hline
\end{tabular}

\subsection{Calibration Result Validation}

In order to verify the accuracy of on-site calibration method, take the calibrated dose instrument to the standard laboratory for testing, the radiation source are ${ }^{137} \mathrm{Cs}$ and ${ }^{60} \mathrm{Co}$, and on-site calibration coefficient and experiment calibration coefficient are listed in Table 8.

The relative error of dose instrument for on-site calibration coefficient and experiment calibration coefficient is $3.4 \%$, the on-site calibration coefficient is relatively large, mainly because the energy of $\mathrm{X}$ ray is low, and it is easily absorbed during transportation in the air or passing through the shell of the detector making the value of dose instrument measurement lower than the true value.

The above results show that it is feasible to calibrate the dose instrument using $\mathrm{X}$ ray, during the calibration process the effect of scattering on dose instrument should be reduce as much as possible.

\section{Conclusion}

This paper combined with Monte Carlo simulation and experiment to establish an on-site calibration method for dose instrument based on $\mathrm{X}$ ray; the calibration result is verified at standard laboratory, and the relative error is $3.4 \%$. It shows that the on-site calibration method is feasible; it works easily and has no radiation hazards to person when it is no work, yet it can solve the problem of measurement accuracy for large area and stationary instruments, and what's more it has an important significance for improving the radiation environmental assessment and radiation safety management level.

\section{Acknowledgements}

We wish to thank Dr. Luo Jianhui and Wei Fuli of Northwest Institute of nuclear technology for their help, they give us experimental guidance and good suggestions throughout this project. 


\section{References}

[1] Huiru, J. and Kexin, W. (2002) Calibration of Radiation Protection Monitoring Instrument. Atomic Energy Press, Beijing.

[2] Nichols, A.L. (1992) IAEA Coordinated Research Programme on X- and Gamma-Ray Standards for Detector Calibration. In: Qaim, S.M., Ed., Nuclear Data for Science and Technology. Research Reports in Physics, Springer, Berlin, Heidelberg, 521-522. https://doi.org/10.1007/978-3-642-58113-7_148

[3] Woods, M.J. (2007) Update of X Ray and Gamma Ray Decay Data Standards for Detector Calibration and Other Applications, Volume 1: Recommended Decay Data, High Energy Gamma Ray Standards and Angular Correlation Coefficients. International Atomic Energy Agency, Vienna.

[4] Yonghua, R. (2016) Research on On-Site Calibration Technology of Fixed $\gamma$ Detector at China Experimental Fast Reactor. Energy Science and Technology, 50, 891894.

[5] Fei, G., Xuefu, X. and Ning, N. (2015) On-Site Calibration Technology for Fixed Environmental Gamma Radiation Rate Meter. Energy Science and Technology, 49, 212-217.

[6] Fei, G., Ning, N., Xue, F., Jinbing, H., Mingzhe, S. and Hongyu, W. (2014) On-Site Calibration of Gamma Radiation Dose Rate Monitor in Environment Automatic Continuously Monitoring Stations. Annual Report of China Institute of Atomic Energy, Atomic Energy Press, Beijing, 310-311.

[7] Fei, G., Xue, F., Ning, N., Mingzhe, S., Jinbing, H. and Hongyu, W. (2014) Development of Portable 137Cs Irradiation Facility and On-Site Calibration. Radiation Protection, 34, 134-137 + 146 .

[8] Fei, G., Ning, N., Mingzhe, S. and Jinbing, H. (2014) Development of Portable Gamma Ray Irradiation Facility for On-Site Calibration. Journal of Astronautic Metrology and Measurement, 5, 34-37 + 54.

[9] Chao, Z., Zhen, Y., Fangdong, T., Linfeng, H., Yihe, X. and Xiaojun, L. (2016) Development of an Irradiation Device for On-Site Calibration of Environmental Gamma Radiation Dose Rate Meter. Nuclear Technology, 39, Article ID: 090201.

[10] Peaple, L.H. and Burt, A.K. (1969) The Measurement of Spectra From X-Ray Machines. Physics in Medicine and Biology, 14, 73-85. https://doi.org/10.1088/0031-9155/14/1/005

[11] Gullayanon, R. (2011) A Calibration Methodology for Energy Dispersive X-Ray Fluorescence Measurements Based upon Synthetically Generated Reference Spectra (Atlanta). PhD Thesis, Georgia Institute of Technology, Atlanta.

[12] Lamperti, P.J., Loftus, T.P. and Loevinger, R. (1988) NBS (National Bureau of Standards) Measurement Services: Calibration of X-Ray and Gamma-Ray Measuring Instruments.

[13] The State Administration of Quality and Technical Supervision (2011) GB/T 12162.1-2000: X and Gamma Reference Radiation for Calibrating Dose Meters and Dose Rate Meters and for Determining Their Response as a Function of Photon Energy Part 1: Radiation Characteristics and Production Methods. Standard Press of China, Beijing.

[14] Geant4 Collaboration (2015) Geant4 User's Guide for Application Developers. CERN.

[15] Yi, L. (2009) Monte Carlo Simulation of Energy Response of Ionization Chamber. Radiation Protection Bulletin, 29, 34-36.

[16] Zhengdong, H., Xunjiang, X., Jianhua, W., Shudong, L. and Jianping, L. (2008) 
Study of the Energy Response of High Pressure Ionization Chamber for High Pressure Ionization Chamber for High Energy Gamma-Ray. Chinese Physics C, 32, 370 372.

[17] Ehrlich, M., Seltzer, S.M., Bielefeld, M.J. and Trombka, J.I. (2005) Spectrometry of a 60 Co Gamma-Ray Beam Used for Instrument Calibration. Metrologia, 12, 169-179. https://doi.org/10.1088/0026-1394/12/4/006

Submit or recommend next manuscript to SCIRP and we will provide best service for you:

Accepting pre-submission inquiries through Email, Facebook, LinkedIn, Twitter, etc. A wide selection of journals (inclusive of 9 subjects, more than 200 journals)

Providing 24-hour high-quality service

User-friendly online submission system

Fair and swift peer-review system

Efficient typesetting and proofreading procedure

Display of the result of downloads and visits, as well as the number of cited articles Maximum dissemination of your research work

Submit your manuscript at: http://papersubmission.scirp.org/

Or contactwjnst@scirp.org 